\title{
A genética e seus desafios no Brasil contemporâneo
}

\author{
Genetics and its challenges in \\ contemporary Brazil
}

\author{
Cristiano Guedes \\ Anis: Instituto de Bioética, \\ Direitos Humanos e Gênero \\ cguedes@unb.br
}

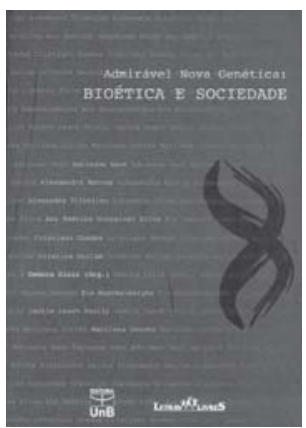

Diniz, Debora (Org.). Admirável nova genética: bioética e sociedade. Brasília: Ed. UnB; LetrasLivres, 2005 344p.

\begin{abstract}
$\mathrm{A}$ genética é um campo cujos avanços têm levantado questões que exigem um esforço interdisciplinar de reflexão. O século XX presenteou a humanidade com descobertas que possibilitaram a identificação e descrição hereditária de doenças ainda desconhecidas no cenário biomédico. Apesar dos avanços científicos, da descoberta de medicamentos e de tratamentos que elevam a qualidade e a expectativa de vida, para grande parte das doenças genéticas a cura ainda não foi encontrada. O tratamento de pessoas com doenças genéticas traz ainda repercussões tanto para as famílias quanto para o Estado. Diante desse cenário, há quem defenda a prevenção de novos casos.

A prevenção em saúde pública por meio de programas de educação em saúde ou interrupção da gravidez são estratégias vigentes em vários países, tais como Cuba e Estados Unidos. No Brasil, contudo, tendo em vista a legislação proibitiva para o aborto, ou mesmo a entrada tímida da genética na saúde pública, o leque de opções é reduzido para os casais com expectativa de ter um filho com determinada doença genética. Esse é um exemplo das questões morais suscitadas pela genética e analisadas, sob diferentes perspectivas disciplinares, no livro Admirável nova genética: bioética e sociedade.

Organizadora do livro e autora de alguns capítulos, a antropóloga Debora Diniz reuniu um grupo de dez pesquisadores que são referência para estudos sobre genética e bioética. A diversidade em termos de área de formação e vínculo institucional é um trunfo do grupo de autores, pois contribui para a amplitude e densidade das análises realizadas. Entre as áreas do saber representadas estão: antropologia, biologia, bioquímica, enfermagem, filosofia, história, medicina e serviço social. Todos os autores são vinculados a centros de pesquisa nacionais ou internacionais que nos últimos anos se destacaram em discussões envolvendo questões éticas na genética, como é o caso do Projeto Genoma Humano. Elaborado no decorrer de cinco anos, o livro reflete discussões que foram iniciadas em programas de pós-graduação, seminários, grupos de trabalho e congressos. O financiamento esteve a cargo da Organização Pan-americana da Saúde (Opas), por meio dos recursos provenientes do Prêmio Manuel Velasco-Suárez de Bioética, que foi criado em 2002 e teve como primeira contemplada a organizadora da obra.

O livro é composto de introdução e cinco partes, divididas segundo a temática explorada. Na introdução, Debora Diniz estabelece um diá-
\end{abstract}


logo com um clássico da ficção, Admirável mundo novo, de Aldous Huxley. Por meio do diálogo estabelecido com essa obra, o leitor é convidado à leitura dos demais capítulos nos quais a genética e o risco do determinismo biológico são questionados sob distintas perspectivas argumentativas. É na introdução que a organizadora apresenta de forma sutil o conceito de 'nova genética', que remete aos termos da relação a ser estabelecida entre genética e direitos humanos, de modo a redescrever o fantasma deixado pelo nazismo. Os experimentos nazistas com humanos e as políticas eugênicas são apontados como exemplos de conseqüência nociva da genética que pode surgir quando direitos humanos deixam de ser reconhecidos. Também na introdução a questão do planejamento familiar, da prevenção de doenças e da autonomia reprodutiva é outro ponto destacado, uma vez que está presente em diversos artigos.

A primeira parte, intitulada Desafio Bioético da Nova Genética, apresenta três capítulos. No primeiro, "O admirável projeto genoma humano", a médica Marilena Corrêa apresenta alguns impactos morais causados pelas descobertas do Projeto Genoma Humano e discute como a bioética tem sido um campo disciplinar favorável à análise desse tema. O segundo capítulo, "Predestinação genética e social: a clonagem de Hitler no filme Meninos do Brasil", tem como autoras Debora Diniz e a enfermeira Ana América Gonçalves, as quais, pela análise do filme de Franklin Schaffner, analisam implicações éticas associadas à possibilidade da clonagem humana. O terceiro capítulo consiste em entrevista realizada por Diniz e Corrêa com o biólogo Dean Hamer, pesquisador que estuda a homossexualidade no campo da genética. A tese de Hamer, largamente contestada nos círculos científicos, é de que haveria um gene para a homossexualidade.

Na segunda parte do livro, o foco do debate é a questão da deficiência, cujo estudo de caso focalizou a surdez. No primeiro artigo, "Cultura Surda: entre a genética e a diversidade cultural", Debora Diniz analisa algumas das especificidades da cultura surda e os desafios para o planejamento familiar e para as políticas relacionadas à deficiência. A autora chama a atenção para uma das estratégias semânticas presentes no debate sobre surdez: "há uma tradição nos estudos sobre surdez de representar a cultura Surda e as pessoas que se identificam com o movimento culturalista da surdez com 's' maiúsculo" (p.42). A autonomia reprodutiva de pessoas surdas é analisada sob o argumento de que a surdez não seria uma deficiência, mas apenas um tipo de diversidade.

O segundo artigo, "Corporificação da deficiência e uma ética do cuidar", tem como autora Jackie Leach Scully, bioquímica e participante do movimento surdo. Scully destaca a importância de contemplar, nos estudos sobre surdez e reprodução, o significado do corpo com deficiência e as implicações que ele representa em torno da concepção de justiça social. Os dois artigos apresentam perspectivas analíticas distintas em torno do tema da surdez e são exemplos de discussões presentes no campo da bioética que têm suscitado debates cada vez mais intensos por meio dos avanços das novas tecnologias reprodutivas. Um dos pontos desse debate consiste em analisar em 
que medida as decisões reprodutivas de pessoas com deficiência podem interferir na vida de gerações futuras e como lidar com o exercício da autonomia reprodutiva quando, por exemplo, há escolha deliberada por embriões com deficiência no caso das novas tecnologias reprodutivas.

A terceira e a quarta partes do livro trazem questões centrais de saúde pública em diferentes países: a anemia falciforme e o aborto. A anemia falciforme é a doença mais prevalente na população brasileira e tem recebido atenção crescente do governo brasileiro, sobretudo na última década, dada a elevada morbidade e mortalidade que representa. Apesar da importância epidemiológica, a anemia falciforme é ainda pouco explorada como um objeto de estudo das ciências humanas e das ciências sociais. Esse é um tema que, desde a década de 1970, ocupa a pauta de discussões de pesquisadores brasileiros provenientes da epidemiologia, da genética ou mesmo da hematologia. Sempre prevaleceu o enfoque biomédico ao se analisar a anemia falciforme no Brasil, e o livro pode ser considerado pioneiro ao colocar no centro do debate da bioética brasileira a questão da anemia falciforme e suas especificidades éticas e sociais.

Intitulada Anemia Falciforme e Desafios de Saúde Pública no Brasil, a terceira parte da obra foi escrita por Debora Diniz em parceria com os assistentes sociais Cristiano Guedes e Alexandra Trivelino. Nessa parte são analisadas ações educativas adotadas pelo governo brasileiro no sentido de prevenir o avanço da anemia falciforme, bem como os desafios humanistas postos pelo debate sanitário. Os autores mostram que as políticas públicas brasileiras instituídas no campo de prevenção e atendimento das pessoas identificadas como portadoras do traço ou da anemia falciforme nem sempre oferecem garantias básicas, como o direito à privacidade ou mesmo a confidencialidade na relação estabelecida entre portadores e profissionais de saúde. As pesquisas apresentadas nessa parte do livro mostram que o Brasil ainda dialoga pouco com outros países ou mesmo desconhece suas experiências no campo da anemia falciforme e, nesse sentido, corre o risco de repetir erros que outros países cometeram no campo da prevenção de doenças genéticas. $\mathrm{O}$ estabelecimento de políticas autoritárias de prevenção e a estigmatização das pessoas identificadas por meio dos testes são riscos que o Brasil corre ao deixar de dialogar com os outros países que possuem uma longa trajetória, repleta de erros e de acertos, nesse campo de intervenção da saúde pública.

A quarta parte do livro tem como título Aborto por Anomalia Fetal e Desafios de Justiça e traz artigos da filósofa Adrienne Asch, de Debora Diniz e da bióloga Alessandra Barros. O artigo de Asch apresenta o 'argumento expressivista', uma tese que durante anos acirrou o debate sobre má-formação fetal nos Estados Unidos. Asch, por meio do argumento expressivista, analisa a mensagem que seria enviada às pessoas com deficiência quando a interrupção da gravidez tem como principal razão evitar o nascimento de uma pessoa com deficiência. Embora considere o aborto como um direito das mulheres, Asch explora duas questões a serem consideradas no debate sobre interrupção da gravidez de fetos com deficiência: "a primeira, que não é qualquer 
feto que é abortado, mas 'aquele feto em particular, porque apresenta determinada característica' e a segunda, que ao abortar um determinado feto em particular, as mulheres enviariam uma 'mensagem negativa' às pessoas com aquela condição" (p.33). $\mathrm{O}$ artigo de Asch é debatido por Diniz e Barros, que dialogam com o argumento expressivista a partir do cenário brasileiro e de suas especificidades em relação ao aborto e à deficiência. Asch destaca que a deficiência não é incompatível com a vida e que as limitações não estão inscritas nos corpos, mas nas sociedades onde vivem as pessoas com deficiência.

O encerramento do livro discute a prática do aconselhamento genético por meio de dois artigos. O primeiro, escrito pela teóloga e historiadora Els Maeckelberghe, tem como título "Aconselhar profissionalmente: aconselhamento genético e autonomia". O artigo de Maeckelberghe é provocativo, uma vez que questiona a centralidade dada aos princípios da 'neutralidade' e da 'não-diretividade' nas sessões de aconselhamento genético. Discute-se a insuficiência de tais princípios como mecanismo de controle social, e a autora chega a propor um novo princípio, que é o da 'autonomia relacional'. No segundo capítulo, "Diagnóstico pré-natal e aconselhamento genético: algumas questões", a médica Cristina Guilam, tendo como referência a proibição do aborto na legislação brasileira e uma pesquisa empírica, mostra como o aconselhamento genético pode ser restrito e assumir um novo significado para os profissionais de saúde brasileiros que atuam nessa área.

Admirável nova genética: bioética e sociedade avança em um diálogo sobre os desafios da genética em países como o Brasil, onde os desenvolvimentos científicos e tecnológicos nem sempre são acompanhados do estabelecimento de mecanismos de controle social voltados à proteção de direitos. Trata-se de um livro para pesquisadores e profissionais de saúde que atuam no campo da nova genética. O livro contribuirá, também, no processo de reflexão em torno de novas legislações e regulamentos destinados a ordenar a vida da sociedade brasileira diante das descobertas científicas e de suas conseqüências sociais. 